
\title{
$\begin{array}{ll}\text { Research Square } & \begin{array}{l}\text { Preprints are preliminary reports that have not undergone peer review. } \\ \text { They should not be considered conclusive, used to inform clinical practice, } \\ \text { or referenced by the media as validated information. }\end{array}\end{array}$
}

\section{Child Perception Questionnaire in Iranian Elementary Schoolers: A Psychometric Study}

\section{Maryam Faghani}

Qom University of Medical Science and Health Services

\section{Aida Mehdipour}

Qom University of Medical Science and Health Services

\section{Elaheh Akbari}

Qom University of Medical Science and Health Services

Mohammadali Amini-Tehrani

Tehran University of Medical Sciences

\section{Atefeh Salehi Armaki}

Qom University of Medical Science and Health Services

\section{Seyed Mohammad Hossein Lajevardi}

Qom University of Medical Science and Health Services

\section{Leila Ghazvinian}

Qom University of Medical Science and Health Services

Hadi Zamanian ( $\nabla$ zamanian@alumnus.tums.ac.ir)

Qom University of Medical Science and Health Services

\section{Research Article}

Keywords: Dental Care for Children, Oral Health, Psychometrics, Quality of life, Self-assessment

Posted Date: January 18th, 2021

DOI: https://doi.org/10.21203/rs.3.rs-145649/v1

License: (c) (i) This work is licensed under a Creative Commons Attribution 4.0 International License. Read Full License 


\section{Abstract}

Background: Child perception questionnaire (CPQ) assessing the oral health-related quality of life (OHQoL) of children is a widely-used instrument in the field. However, the instrument has not undergone validation and psychometric evaluation in Iranian population of children. The study aimed at examining the construct validity and testing the reliability of CPQ-16 in 7-12-year-old Persian-speaking elementary schoolers.

Methods: From two main cities in 2018, Iran, 708 mother-child dyads were enrolled in this cross-sectional study. Questionnaires were executed via interviewer-administered method. DMFT and dmft indexes were examined for divergent validity. Two built-in indexes of overall oral health $(\mathrm{OOH})$ and overall well-being $(\mathrm{OW})$ were used for concurrent validity. Exploratory factor analysis (EFA) with Geomin rotation, Cronbach's alpha, and Spearman's correlation were executed.

Results: Overall, 695 data entered the analysis. Children' mean age was 9.72 (1.36) years. EFA indicated 11 items to compose three eligible factors, including oral problems, emotional problems, and social problems. Except for social well-being and emotional well-being, all OHQoL variables were correlated. CPQ-16, CPQ-11, and the subscales indicated significant relationships with overall oral health, except for social wellbeing. CPQ-11 compared to CPQ-16 showed a slightly higher correlation with $\mathrm{OOH}$ index. Only CPQ-11 and emotional well-being indicated significant associations with $\mathrm{OW}$ index. Whereas only emotional well-being indicated high DMFT, the CPQ-16, CPQ-11 and oral problems were associated with dmft. Cronbach's alpha was 0.66.

Conclusions: Further research on clinical sample is needed. Practitioners are suggested employing CPQ to multidimensionally examine the children's' oral health needs.

\section{Background}

The World Dental Federation (FDI) defines oral health as a multifaceted phenomenon that entails "the ability to speak, smile, smell, taste, touch, chew, swallow, and convey a range of emotions through facial expressions with confidence and without pain, discomfort, and disease of the craniofacial complex"[1]. Oral health can be assessed through both objective and subjective approaches. In the objective approach, the oral health is assessed by medical professionals using different dentistry, orthodontic, and endodontic methods to identify diseases and decays, and delivery of treatments required for the patient. However, in the subjective approach, oral health is assessed based on the patient's perception of his/ her dental problems, illnesses, and treatments required [2]. Based on this categorization, oral healthrelated quality of life (OHRQoL) approaches the oral health in subjective manner. In this regard, the most comprehensive definition of oral health is provided by the US Surgeon General that defines OHRQoL as "a multidimensional construct that reflects individual's comfort when eating, sleeping, and engaging in social interaction, their self-esteem, and satisfaction with respect to oral health." [3]

Research show that childhood oral health predicts oral health in adulthood, and assessment of children's OHRQoL plays a pivotal role in their oral health [4]. Hence, given the importance of childhood oral health for adulthood and the increasing importance of oral health in the psychosocial aspects of life, necessity access to an instrument to assess OHRQoL in Iranian students is undeniable. Moreover, the OHRQoL assessment is both theoretically and clinically of great importance. For example, oral health plays a role in general health and overall QoL [5]. Moreover, patient selfreport scales have become as a source of decision-making in clinical settings [6]. Ultimately, OHRQoL should be seen as a salient assessment need for the community's oral health, to reduce social inequalities in this area of health and provide organized oral health care for the community members [7]. 
To accomplish these goals, various instruments are developed and standardized to assess OHRQoL in the pediatric population, of which the child perception questionnaire (CPQ) is one of the most widely used OHRQoL assessment tools in children [14] developed by Jokovic et al., (2002) in Canada for children aged 11-14 years [8]. CPQ11-14 measures four domains of oral symptoms, functional limitations, emotional well-being, and social well-being in 37-, 16-, and 8-item versions scored based on a five-point Likert scale [9]. CPQ is employed in Chinese, Brazilian, Danish, German, and Arabic populations and is adapted for ages 8-10 years [10]. To the best of authors' knowledge, CPQ was also utilized by two Iranian studies $[11,12]$ with modifications and combination in other instruments, but it is not systematically and rigorously evaluated for validity and reliability so far. Due to the need for an accurate and reliable instrument to assess OHRQoL in Persian-Speaking children residing in Iran, and considering the research needs in psychosocial aspects of oral health, the present study aimed at translating the CPQ into Persian language and evaluating its validity and reliability in Persian-speaking elementary schoolers.

\section{Methods}

\section{Sample and Design}

This cross-sectional study aiming at validation of Persian version of CPQ-16 instrument was a part of Children's Dental Health Research Project (CDHRP-2018) conducted on elementary schoolers aged 7-12 years in Qom and Kashan cities, Iran, from January to April 2018. In the present study, 712 students were enrolled following an announcement to the parents. Exclusion criteria included any medical prohibition, long-term use of medicinal and psychiatric drugs (over one year), and the child's inability to independently answer the questions, and apparent disability. The voluntary sampling method was used. Written Informed consent was obtained from the parents, children orally confirmed their consent. All methods were carried out in accordance with relevant guidelines and regulations.

\section{Measures}

Demographic information: A questionnaire was used to obtain demographic characteristics of the child, including age, grade, and parental educational level, parental occupation.

The child perception questionnaire (CPQ-16) is a self-report scale for children aged 11-14 years developed by Jokovic in Toronto, Canada, and two short-forms of it were also introduced thereafter [9]. The 16-item scale measures four areas of oral symptoms, functional limitations, emotional well-being, and social well-being. Each area contains four items based on a five-point Likert scale. In total, a certain score is given to each subscale and total score of 16 to 80 to each individual. A higher score indicates a lower OHRQoL for the child. In the original study to develop the instrument [9], the relationship of CPQ11-14 with overall oral health and the affected overall well-being indicated good construct validity of the instrument. The internal consistency of the items was 0.91 using Cronbach's alpha and its ICC correlation coefficient was 0.90 , which confirmed its reliability [9].

The 17th and 18th questions added to the CPQ-16 were originally devised for evaluating the construct validity of the scale. Overall oral health question asks the child "In general, how do you feel about the health of your teeth, jaws, lips, and mouth." [9] The child is supposed to rate his/her overall oral health on a scope of excellent (5), very good (4), good (3), average (2) and poor (1). Overall well-being question asks the child "In general, how the status of your teeth, jaws, lips, or mouth affected your life?" [9], assessing the perceived impact of overall oral health on the child's well-being. A scale of never (0), very low (1), somewhat (2), high (3) and very high (4) is used to score the items.

Teeth decay index: Decayed, missing, and filled teeth (DMFT/dmft) were assessed based on the criteria set by WHO [13], to evaluate the divergent validity. A cotton roll and a dental mirror were utilized for dental examinations. The 
examinations were executed by trained and calibrated dentistry students under the supervision of the second author. For calibration, the examiners performed 12 examinations during two weeks before conducting the study. A kappa score of .90 was reached.

\section{Translation}

The standard method of forward-backward translation was employed to translate the CPQ-16 [14]. In this method, the questionnaire is first translated separately into Persian language by two English to Persian translators. Then, the two translations are confronted to be evaluated in terms of word-choice and semantic equivalency. The resulted final Persian draft is then translated back into English language by an expert translator, to ensure the semantic and conceptual equivalence of the Translated draft. To ensure the face validity, the Persian CPQ-16 was performed in a pilot study on 10 elementary school children referring to dental centers.

\section{Data Analysis}

To analyze the data, SPSS version 24 software was used. Descriptive statistics were also employed and data were expressed as mean, standard deviation, and frequency. Employing Mplus software V. 7.4 [15], several exploratory factor analyses (EFA) to extract three to five factors were carried out, with Full Information Maximum Likelihood for managing missing data and with MLR estimator as well as Varimax and Geomin rotation methods. After establishing the structure of the main scale, Spearman correlation coefficient was used to examine the relationship of DMFT index with total and subscale scores of CPQ as the differential validity. A positive and significant correlation can confirm the differential validity of the instrument. Spearman correlation coefficient was used to examine the relationship between overall oral health, its perceived effect on child's well-being, and the number of teeth brushing times per day with total and subscale scores of $\mathrm{CPQ}$ as convergent validity. A positive and significant correlation can confirm the convergent validity of the instrument. Validity was also examined using Pearson correlation coefficient between the subscales. The internal consistency reliability was also explored using Cronbach's alpha coefficient $(>0.70)$.

\section{Results}

\section{Sample Characteristics}

Table 1 reports the demographic characteristics of the study sample. .From 708 participants enrolled in the study, 13 data was completely missing. Therefore, the sample size reached 695 caregiver-child dyads. The mothers' and children's mean age was respectively 36.33 (5.37 range: 20 to 55 year-old) and 9.72 years (1.36; range: 7 to 12 yearold). 
Table 1

Sample Characteristics ( $N=695)$

\begin{tabular}{|c|c|}
\hline Characteristics & $\mathrm{n}(\%)$ \\
\hline \multicolumn{2}{|l|}{ City of residence } \\
\hline Qom & $313(45)$ \\
\hline Kashan & $382(55)$ \\
\hline \multicolumn{2}{|l|}{ Child's gender } \\
\hline Female & $532(76.5)$ \\
\hline Male & $163(23.5)$ \\
\hline \multicolumn{2}{|l|}{ Child's grade } \\
\hline Second & $158(22.8)$ \\
\hline Third & $121(17.5)$ \\
\hline Fourth & 218 (31.5) \\
\hline Fifth & 195 (28.2) \\
\hline \multicolumn{2}{|l|}{ Nationality } \\
\hline Iranian & $651(94.9)$ \\
\hline Non-Iranian & $35(5.1)$ \\
\hline \multicolumn{2}{|l|}{ Ethnicity } \\
\hline Fars & $467(69.4)$ \\
\hline Kurd & $14(2.1)$ \\
\hline Lur & $14(2.1)$ \\
\hline Bakhtiari & $2(0.3)$ \\
\hline Arab & $6(0.9)$ \\
\hline Turk & $140(20.8)$ \\
\hline Afghan & $30(4.5)$ \\
\hline \multicolumn{2}{|c|}{ Mother's marital status } \\
\hline Married & 649 (97.3) \\
\hline Divorced/widow & $18(2.7)$ \\
\hline \multicolumn{2}{|c|}{ Mother's education } \\
\hline Under Diploma & $267(40)$ \\
\hline Undergraduate & $258(38.7)$ \\
\hline Graduate & $142(21.3)$ \\
\hline Mother's occupat & \\
\hline
\end{tabular}




\begin{tabular}{|lc|}
\hline Characteristics & $\mathbf{n}(\%)$ \\
\hline Working & $83(12.2)$ \\
\hline Housewife & $60(87.8)$ \\
\hline Insurance & \\
\hline Yes & $523(80.5)$ \\
\hline No & $127(19.5)$ \\
\hline Monthly household income & \\
\hline Low (<500 USD) & $74(18.8)$ \\
\hline High ( $\geq 500$ USD) & $321(81.2)$ \\
\hline \multicolumn{2}{|l}{ Note. Percentage is reported as valid. } \\
\hline
\end{tabular}

\section{Item-total analysis}

The item-total analysis was carried out with list-wise deletion on 644 data. Table 2 shows the details of items statistics and item-total analysis. The total Cronbach's alpha was 0.71 . Item means was 1.98 , ranged from 1.34 to 2.88 . The scale's mean (SD) was 31.66 (7.43). As Table 2 presents, the squared multiple correlations were estimated from 0.08 to 0.32 ; these results indicated that item\#1 and \#8 were accounted for by all the remaining items with the least variance, whereas the variance accounted for was the highest for item\#11. However, the total Cronbach's alpha did not substantially increase upon eliminating any item. 
Table 2

Item-Total Statistics of CPQ-16

\begin{tabular}{|c|c|c|c|c|c|c|c|c|}
\hline \multirow[t]{2}{*}{ Items } & \multirow[t]{2}{*}{ Content } & \multicolumn{3}{|c|}{ Item Level } & \multicolumn{4}{|c|}{ Item-Total Level ( $N=644)$} \\
\hline & & $\mathbf{N}$ & $\stackrel{M}{\text { (SD) }}$ & Skewness & Kurtosis & $\begin{array}{l}\text { Corrected } \\
\text { Item-Total } \\
\text { Correlation }\end{array}$ & $\begin{array}{l}\text { Squared } \\
\text { Multiple } \\
\text { Correlation }\end{array}$ & $\begin{array}{l}\text { Cronbach's } \\
\text { Alpha if } \\
\text { Item } \\
\text { Deleted }\end{array}$ \\
\hline cpq1 & Mouth Soars & 694 & $\begin{array}{l}1.75 \\
(.91)\end{array}$ & 1.08 & .46 & .190 & .082 & .703 \\
\hline cpq2 & Bad Breath & 692 & $\begin{array}{l}2.36 \\
91.22)\end{array}$ & .46 & -.71 & .270 & .136 & .697 \\
\hline cpq3 & $\begin{array}{l}\text { Food caught in } \\
\text { teeth }\end{array}$ & 693 & $\begin{array}{l}2.88 \\
(1.12)\end{array}$ & -.02 & -.43 & .314 & .159 & .691 \\
\hline cpq4 & Chewing Problems & 693 & $\begin{array}{l}1.76 \\
(1.12)\end{array}$ & 1.28 & .60 & .367 & .167 & .685 \\
\hline cpq5 & $\begin{array}{l}\text { Difficulty in } \\
\text { eating/drinking hot } \\
\text { or cold foods }\end{array}$ & 694 & $\begin{array}{l}2.00 \\
(1.18)\end{array}$ & .80 & -.50 & .374 & .195 & .684 \\
\hline cpq6 & Utterance problems & 691 & $\begin{array}{l}1.34 \\
(.73)\end{array}$ & 2.34 & 5.51 & .194 & .068 & .702 \\
\hline cpq7 & Pain in mouth/teen & 687 & $\begin{array}{l}1.96 \\
(.99)\end{array}$ & .78 & -.08 & .380 & .166 & .685 \\
\hline cpq8 & Taking longer to eat & 687 & $\begin{array}{l}2.50 \\
(1.42)\end{array}$ & .37 & -1.15 & .177 & .083 & .712 \\
\hline cpq9 & Irritation/frustration & 689 & $\begin{array}{l}1.81 \\
(1.07)\end{array}$ & 1.01 & -.17 & .390 & .287 & .683 \\
\hline cpq10 & Embarrassment & 692 & $\begin{array}{l}2.55 \\
(1.30)\end{array}$ & .22 & -1.08 & .383 & .263 & .682 \\
\hline cpq11 & Upset & 686 & $\begin{array}{l}2.55 \\
(1.19)\end{array}$ & .16 & -.93 & .437 & .315 & .676 \\
\hline cpq12 & $\begin{array}{l}\text { Worrying about } \\
\text { how other people } \\
\text { think }\end{array}$ & 691 & $\begin{array}{l}1.71 \\
(1.08)\end{array}$ & 1.30 & .57 & .318 & .171 & .691 \\
\hline cpq13 & $\begin{array}{l}\text { Avoiding } \\
\text { smile/laughing }\end{array}$ & 693 & $\begin{array}{l}1.44 \\
(.91)\end{array}$ & 2.07 & 3.53 & .281 & .118 & .695 \\
\hline cpq14 & Teased/labeled & 694 & $\begin{array}{l}1.78 \\
(1.06)\end{array}$ & 1.16 & .35 & .312 & .124 & .691 \\
\hline cpq15 & Asked questions & 688 & $\begin{array}{l}1.39 \\
(.74)\end{array}$ & 2.06 & 4.11 & .270 & .163 & .697 \\
\hline cpq16 & Argued with others & 692 & $\begin{array}{l}1.97 \\
(1.05)\end{array}$ & .80 & -.22 & .195 & .100 & .704 \\
\hline
\end{tabular}


EFA to extract three to five factors were carried out. EFA revealed that the fifth factor did not include any significant factor loading and the fourth factor only could include one item. Also, it was consistently revealed that items including cpq5, $6,8,13$, and 14 could not reach to the least eligible factor loading of 0.32 on any factor. Consequently, excluding those five items, the final EFA deriving three factors showed the best performance (Chi-square [25] $=41.331, P=.021$, scaling correction factor $=1.0470, \mathrm{RMSEA}=.031[.012, .047]$, PCLOSE $=.987, \mathrm{CFI}=.975, \mathrm{TLI}=.944, \mathrm{SRMR}=.021$ ) Table 3 shows the factors, the factor loadings after Geomin rotation, and details of EFA for 11 retained items.

Table 3

Factor Analysis on the Eleven Retained Items of CPQ-16 (N=694)

\begin{tabular}{|c|c|c|c|}
\hline \multirow[t]{2}{*}{ Items } & \multicolumn{3}{|l|}{ Factors } \\
\hline & Oral Problems & Emotional Problems & Social Problems \\
\hline cpq1 & $0.372 *(0.069)$ & -0.026 & -0.002 \\
\hline cpq2 & $0.469 *(0.071)$ & -0.006 & -0.043 \\
\hline cpq3 & $0.489 *(0.073)$ & -0.035 & 0.029 \\
\hline cpq4 & $0.403^{*}(0.074)$ & 0.008 & $0.172^{*}$ \\
\hline cpq7 & $0.366 *(0.072)$ & 0.077 & 0.140 \\
\hline cpq9 & -0.026 & $0.639 *(0.065)$ & 0.091 \\
\hline cpq10 & 0.023 & $0.575^{\star}(0.063)$ & 0.029 \\
\hline cpq11 & $0.223^{*}$ & $0.557 *(0.061)$ & -0.020 \\
\hline cpq12 & 0.009 & $0.365^{*}(0.064)$ & $0.217 *$ \\
\hline cpq15 & 0.015 & 0.007 & $0.496 *(0.119)$ \\
\hline cpq16 & -0.006 & -0.086 & $0.531 *(0.111)$ \\
\hline Eigenvalue & 2.542 & 1.355 & 1.221 \\
\hline $0.66(\mathrm{~N}=653)$ & 0.54 & 0.66 & 0.41 \\
\hline
\end{tabular}

\section{Concurrent Validity}

Table 4 shows the Spearman's correlations between OHRQOL scores, perceived overall oral health, perceived overall well-being, DMFT, and dmft. Inspection from the table indicates that there were significantly positive correlations between each pair of CPQ's factors and total scores, except for social well-being and emotional well-being. Also, both total scores and subscales had significant relationships with the perceived overall oral health, except for social wellbeing. Besides, the adjusted CPQ score compared to the total score indicated a slightly higher correlation with overall oral health. On the other hand, only adjusted CPQ score indicated a weak yet significant association with overall well-being, which was true for emotional well-being as well. Furthermore, the OHQOL variables mainly indicated significant associations with dmft, rather than DMFT. In that, whereas only emotional well-being showed a significant correlation with DMFT, both of total CPQ and its adjusted score as well as oral health indicated significant 
relationships with dmft. Overall, correlational analysis confirmed the concurrent validity of the CPQ-16, CPQ-11, and the derivative factors.

Table 4

Spearman's Correlation Matrix $(\mathrm{N}=694)$

\begin{tabular}{|c|c|c|c|c|c|c|c|c|c|c|c|c|}
\hline \multicolumn{2}{|c|}{ Variables } & & \multirow{2}{*}{$\begin{array}{l}M(S D) \\
1.98(.46)\end{array}$} & \multirow{2}{*}{$\begin{array}{l}1 \\
1\end{array}$} & \multirow[t]{2}{*}{2} & \multirow[t]{2}{*}{3} & \multirow[t]{2}{*}{4} & \multirow[t]{2}{*}{5} & \multirow[t]{2}{*}{6} & \multirow[t]{2}{*}{7} & \multirow[t]{2}{*}{8} & \multirow[t]{2}{*}{9} \\
\hline 1 & CPQ-16 & & & & & & & & & & & \\
\hline 2 & CPQ-11 & 695 & $2.06(.51)$ & $.93^{\star \star \star}$ & 1 & & & & & & & \\
\hline 3 & Oral Problems & 695 & $2.14(.64)$ & $.71^{\star \star \star}$ & $.77^{\star \star \star}$ & 1 & & & & & & \\
\hline 4 & $\begin{array}{l}\text { Emotional } \\
\text { Problems }\end{array}$ & 695 & $2.16(.82)$ & $.73^{\star \star \star}$ & $.78^{\star \star \star}$ & $.31^{\star * *}$ & 1 & & & & & \\
\hline 5 & Social Problems & 694 & $1.68(.73)$ & $.35^{\star \star \star}$ & $.34^{\star \star \star}$ & $.16^{\star \star \star}$ & .04 & 1 & & & & \\
\hline 6 & $\begin{array}{l}\text { Overall Oral } \\
\text { Health }\end{array}$ & 694 & $\begin{array}{l}2.88 \\
(1.08)\end{array}$ & $.29^{\star \star \star}$ & $.32^{\star \star \star}$ & $.26^{\star \star \star}$ & $.28^{\star \star \star}$ & -.04 & 1 & & & \\
\hline 7 & Overall Well-being & 692 & $\begin{array}{l}3.47 \\
(1.48)\end{array}$ & .06 & $.08^{*}$ & -.02 & $.12^{\star \star}$ & .03 & -.02 & 1 & & \\
\hline 8 & DMFT & 691 & $\begin{array}{l}2.01 \\
(1.85)\end{array}$ & .05 & .06 & -.03 & $.10^{\star \star \star}$ & .03 & .05 & $.08^{*}$ & 1 & \\
\hline 9 & $\mathrm{dmft}$ & 692 & $\begin{array}{l}4.33 \\
(3.41)\end{array}$ & $.09^{*}$ & $.10^{\star \star}$ & $.18^{\star \star \star}$ & -.02 & .04 & $.11^{\star \star}$ & .03 & $-.10^{\star}$ & 1 \\
\hline
\end{tabular}

\section{Discussion}

The current study aimed at translating and testing the psychometric properties of CPQ-16 in a population of Iranian elementary schoolers. The mean OHRQoL in Iranian children was above average, indicating the worse condition in oral health. An global study aggregating scores from 11 countries reported that the mean OHRQoL based on the CPQ-16 was $11.7 \pm 0.9$ in Oceania (New Zealand and Australia), $11.7 \pm 0.7$ in Asia (Cambodia, Brunei, Malaysia, Hong Kong, Thailand), $12 \pm 0.1$ in Europe (Germany and the United Kingdom), $12.6 \pm 0.1$ in Latin America (Mexico and Brazil), and the total mean score of $11.9 \pm 0.9$ [16]. Although this information is not statistically comparable, the OHRQoL score of the studied samples selected from of a general, rather than a clinical, population indicated the need for paying critical attention to the oral health status of this stratum of the community.

The results showed that the internal consistency of the Persian version of CPQ was 0.71 using Cronbach's alpha coefficient. Other studies, likewise, indicated its high internal consistency. In the original study by Jokovic et al. [9], reported an internal consistency of 0.83 . Similarly, the Cronbach alpha of CPQ-16 was 0.81 in a study in Saudi Arabia [17] and 0.82 in Cambodia [18]; also, it was 0.83 for full-form CPQ in New Zealand [19] and 0.96 in Brazil [20]. It should be noted that the Cronbach's alpha coefficient is not a constant, but a specific feature of the sample on which the questionnaire is performed [21]. In fact, consistency in the results of different studies indicates stability in the internal consistency of the instrument.

The EFA showed that by eliminating five items, a three-factor structure including oral problems, emotional well-being, and social well-being is achieved. This factor structure indicates the combination of the two main subscales of oral 
symptoms and functional limitations, in addition to re-exposing the two subscales of emotional well-being and social well-being. The developers' studies $[8,9]$ and other studies providing the translated versions of CPQ did not use EFA to determine its factor structure and validity; only a Spanish language study on the Chilean children sample and a global study of large scale examined its factor structure using exploratory and confirmatory method [16, 22]. According to CFA on the Chilean sample [22] the four-dimensional factor structure of the 16- and 8-item CPQ11-14 was confirmed, but factor structure of the original 37-item was not confirmed. The globally-representative study by Thomson et al. [16] showed that a two-factor structure consisting of oral symptoms and functional limitations similar to that of the current study with the combination of emotional well-being and social well-being could explain the variance of the instrument. Therefore, the results of the present study were empirically valid.

In the factor structure of the present study, the minimum of factor loading of 0.4 was not met for the two items of "pain" and "worrying about others' thoughts", conditioned the items to account for more than $10 \%$ of the variance of the construct. In addition, elimination of five items on problems with eating hot and cold food, speech difficulties, lengthening of meal duration, being annoyed and being ridiculed by others was possibly because they are the characteristics of a clinical population that was not involved in the present sample. To pursue this issue, the EFA was repeated on a sample with minimum DMFT of 1, and the results showed that items 6 and 8 (speech difficulty and lengthening of meal duration, respectively) had no significant loads on both the 3- and 5-factor structures. This suggests that the rarity of such experiences possibly influenced the results.

Concurrent validity of total and subscale scores was confirmed referring to overall oral health and overall well-being and DMFT and dmft indices. The results showed that social well-being and emotional well-being were not correlated; this indicates that the diversity of interpersonal-social and subjective experiences of children regarding their oral health status did not necessarily correlate. Despite relatively strong findings of the current study about the relationship between OHQoL and perceived indices, in the study by Jokovic et al. [9], a weak correlation (0.2) was found between total scores of the instrument and overall oral health. Accordingly, a study in Denmark showed a weak correlation between total and subscale scores and overall oral health; i.e., two subscales of emotional well-being and social wellbeing did not show a relationship with perceived overall health [23]. However, in the study in Saudi Arabia [17] except for the social well-being, other subscales and total score had a significant and positive relationship with overall health. In addition, the results of the present study were consistent with those of the study in Saudi Arabia [17] in which the total score and scores of subscales oral symptoms, functional limitation, and emotional well-being had positive and significant correlation with perceived overall oral health, which confirmed the validity of the instrument. In addition, referring to the correlation of total score and scores of subscales with overall well-being, concurrent validity indicated "the effect of oral health status on individual's life" in the current study; hence, only the modified total score and the score of emotional well-being subscale were correlated with overall well-being. These results were inconsistent with those of the original study [9] as well as the studies in Denmark [23] and Brazil [20] in which all subscales and total scores had a positive and significant correlation with the child's perceived well-being. Nevertheless, the findings suggested that the oral health status of elementary schoolers is associated with their emotional well-being.

Moreover, the OHQoL variables were significantly correlated with the dmft index, and it was only the emotional wellbeing that was associated with the DMFT index. This finding indicates that the continuity of unhealthy condition of primary teeth in pre-school period might be transferred to elementary school age and threatens the OHQOL of the child. However, permanent teeth mainly cause a subjective concern. Previous studies also indicated that total and subscales scores of CPQ11-14 had different relationships with tooth caries index. For example, a Korean study showed that in spite of a positive and significant relationship of oral symptoms, emotional well-being, and total OHQoL with the number of filled teeth, no relationship was found between CPQ11-14 and overall DMFT index [24]. In the study in Saudi Arabia, only a positive correlation was reported between DMFT index and functional limitation [17]. However, the study 
on Chilean children [22] showed that, except oral symptoms, all the subscales had a significant and positive relationship with tooth caries index, which were due to a significant relationship with the number of decayed teeth. As a result, it seems that OHRQoL can show different relationships with caries indices for primary and permanent teeth, both of which are highly dependent on the developmental age of the child. Since the importance of DMFT index in determining oral health status is emphasized [25], further studies on the relationship between OHRQoL and these indices are required.

Generally, the current study findings confirmed the validity and reliability of CPQ and showed that the OHRQoL of children determined by CPQ-16 is correlated with their overall oral health, overall well-being, and oral health behavior. The CPQ-16 is a short-form instrument that can be used to evaluate different aspects of children's OHRQoL in clinical practice. Since childhood is a critical stage in both promoting oral health and learning an oral health promotion lifestyle in adulthood, being informed about the various aspects of OHRQoL can help dentists to match their services with a more comprehensive evaluation. The CPQ-16 can be used in situational surveys as well as epidemiological and longitudinal studies. It can provide valuable information from children about various aspects of their lives affected by their oral conditions. Besides, its traceable results can be used as an evidence to evaluate the promotional programs or restorative interventions to improve oral health in children.

The present study had some limitations, which led the authors to interpret the results with caution. Although the schools were selected randomly, the sample were recruited from who voluntarily would like to have oral check-ups. Thus, a sample involving children with diagnosed oral problems and abnormalities is needed to assess the validity and reliability of the scale in clinical settings. In addition, the studied sample consisted only of students from the two cities of Qom and Kashan. Therefore, generalization of the results to the population of Iranian children should be performed with caution. In the present study, the reliability of CPQ-16 was assessed only by the internal consistency and not by test-retest method that shows the stability of the measurements over time.

\section{Conclusion}

The current study aimed at translating and reporting the psychometric properties of the 16-item CPQ11-14 on a sample of Iranian elementary schoolers, aged 7-12 years. The results showed that Iranian children's OHRQoL is relatively good, but should seriously be promoted. Also, CPQ had an appropriate construct validity including 11 items and subscales on oral problems, emotional well-being, and social well-being in the Iranian sample. The reliability of the instrument was also acceptable. The convergent validity of the total score, modified total score, and subscales scores was confirmed, although social well-being requires further investigations.

\section{Declarations}

\section{Ethics approval and consent to participate}

Written informed consent was obtained from the parents; children were also asked to provide verbal consent in order to participate in the study. The current study protocol was approved by ethics committee of Qom University of Medical Sciences.

\section{Consent for publication}

Official permission was obtained from the developers of CPQ-16 for its standardization, translation, and utilization.

\section{Availability of data and materials}


The datasets generated and/or analysed during the current study are not publicly available but are available from the corresponding author on reasonable request.

\section{Competing interests}

None.

\section{Funding}

The study project was self-funded.

\section{Authors' contributions}

MF contributed to the dental examinations and administration; AM supervised the dental examinations and proofread the manuscript; EA contributed to the dental examinations and administration; MAT contributed data analysis, interpretation, and drafting the manuscript. ASA, SMHL, LG contributed to the survey and data entry of the project; $\mathrm{HZ}$ contributed to conceptual design and proofread the manuscript. All authors contributed to critical reviewing of the manuscript and approved the final manuscript.

\section{Acknowledgements}

This manuscript, as the first author's thesis in doctor of dentistry, was a part of a large-scale study investigating psychosocial determinants of Iranian elementary schoolers' oral health status and behavior. Authors express their gratitude to the participants. We are also thankful for the support provided by the managers and staff of the host schools. The project received no funding. Authors declare that they had no conflict of interest with regards to any aspects of the study.

\section{Funding}

The study was self-funded.

\section{References}

1. Glick M, Williams DM, Kleinman DV, Vujicic M, Watt RG, Weyant RJ. A new definition for oral health developed by the FDI\&\#xa0;World Dental Federation opens the door to a universal definition of oral health. The Journal of the American Dental Association. 2016;147(12):915-7.

2. Cunningham SJ, Hunt NP. Quality of life and its importance in orthodontics. J Orthod. 2001;28(2):152-8.

3. Oral Health in America: A Report of the Surgeon General. US Department of Health and Human Services. Executive Summary. Rockville. MD: National Institute of Dental and Craniofacial Research., 2000.

4. Peres KG, Peres MA, Araujo CL, Menezes AM, Hallal PC. Social and dental status along the life course and oral health impacts in adolescents: a population-based birth cohort. Health Qual Life Outcomes. 2009;7:95.

5. Sheiham A. Oral health, general health and quality of life. Bulletin of the World Health Organization. 2005;83(9):641.

6. Sischo L, Broder HL. Oral health-related quality of life: what, why, how, and future implications. J Dent Res. 2011;90(11):1264-70.

7. Locker D. Disparities in oral health-related quality of life in a population of Canadian children. Community Dent Oral Epidemiol. 2007;35(5):348-56. 
8. Jokovic A, Locker D, Stephens M, Kenny D, Tompson B, Guyatt G. Validity and reliability of a questionnaire for measuring child oral-health-related quality of life. J Dent Res. 2002;81(7):459-63.

9. Jokovic A, Locker D, Guyatt G. Short forms of the Child Perceptions Questionnaire for 11-14-year-old children (CPQ(11-14)): Development and initial evaluation. Health and Quality of Life Outcomes. 2006;4:4-.

10. Gilchrist F, Rodd H, Deery C, Marshman Z. Assessment of the quality of measures of child oral health-related quality of life. BMC Oral Health. 2014;14:40-

11. Heravi F, Farzanegan F, Tabatabaee M, Sadeghi M. Do Malocclusions Affect the Oral Health-related Quality of Life? Oral Health Prev Dent. 2011;9(3):229-33.

12. Farzanegan F, Heravi F, Sooratgar A, Dastmalchi P. Evaluation of relationship between oral health-related quality of life and occlusion traits among female adolescents. Dent Res J (Isfahan). 2014;11(6):684-8.

13. World Health Organization. Oral Health Surveys-Basic Methods. 5th ed. Geneva: World Health Organization; 2013.

14. Sartorius N, Kuyken W. Translation of Health Status Instruments. In: Orley J, Kuyken W, editors. Quality of Life Assessment: International Perspectives. Berlin, Heidelberg: Springer; 1994. p. 3-18.

15. Muthen L, Muthen B. Mplus Version 7 User's Guide: Version 7. Los Angeles, CA: Muthen \& Muthen, 1998-2012.

16. Thomson WM, Foster Page LA, Robinson PG, Do LG, Traebert J, Mohamed AR, et al. Psychometric assessment of the short-form Child Perceptions Questionnaire: an international collaborative study. Community dentistry and oral epidemiology. 2016;44(6):549-56.

17. Brown A, Al-Khayal Z. Validity and reliability of the Arabic translation of the child oral-health-related quality of life questionnaire (CPQ11-14) in Saudi Arabia. Int J Paediatr Dent. 2006;16(6):405-11.

18. Turton BJ, Thomson WM, Foster Page LA, Saub RB, Razak IA. Validation of an oral health-related quality of life measure for Cambodian children. Asia Pac J Public Health. 2015;27(2):NP2339-NP49.

19. Foster Page LA, Boyd D, Thomson WM. Do we need more than one Child Perceptions Questionnaire for children and adolescents? BMC Oral Health. 2013;13:26-.

20. Barbosa TS, Tureli MCM, Gavião MBD. Validity and reliability of the Child Perceptions Questionnaires applied in Brazilian children. BMC Oral Health. 2009;9:13-.

21. Tavakol M, Dennick R. Making sense of Cronbach's alpha. International Journal of Medical Education. 2011;2:535.

22. Núñez Franz L, Rey Clericus R, Bravo-Cavicchioli D, Jiménez Del Río P, Fernández Gonzalez C, Mejía Delgado G. Adaptation and validation of the Spanish version of Child Perception Questionnaire CPQ-Spn11-14 in a Chilean community population. Rev Esp Salud Publica. 2015;89(6):585-95.

23. Wogelius P, Gjørup H, Haubek D, Lopez R, Poulsen S. Development of Danish version of child oral-health-related quality of life questionnaires (CPQ8-10 and CPQ11-14). BMC Oral Health. 2009;9(1):11.

24. Shin H-S, Han D-H, Shin M-S, Lee H-J, Kim M-S, Kim H-D. Korean version of child perceptions questionnaire and dental caries among Korean children. PLoS One. 2015;10(2):e0116011-e.

25. Kay EJ, Mills I, Tredwin C, Lambe P, Nassani MZ. Comparison of utility weighted DMFT with patient-reported oral well-being. J Oral Rehabil. 2014;41(2):155-61. 